\title{
Liquid Drugs and High Dead Space Syringes May Keep HIV and HCV Prevalence High - A Comparison of Hungary and Lithuania
}

\author{
V. Anna Gyarmathy ${ }^{a, b} \quad$ Alan Neaigus $^{c}$ Nan Li $^{b} \quad$ Eszter Ujhelyi $^{d}$ \\ Irma Caplinskiene ${ }^{e, f}$ Saulius Caplinskas ${ }^{e, f}$ Carl A. Latkin ${ }^{b}$ \\ aEuropean Monitoring Centre for Drugs and Drug Addiction, Lisbon, Portugal; ' Johns Hopkins Bloomberg School \\ of Public Health, Baltimore, Md., and 'Mailman School of Public Health, Columbia University, New York, N.Y., \\ USA; ${ }^{d}$ Szent László Hospital, Budapest, Hungary; ${ }^{e}$ Centre for Communicable Diseases and AIDS and ${ }^{\mathrm{f}} \mathrm{M}$. Romerius \\ University, Social Policy Faculty, Vilnius, Lithuania
}

\section{Key Words}

Drugs sold in liquid form $\cdot$ Hungary $\cdot$ Injecting drug use $\cdot$

Lithuania $\cdot$ Syringe type

\begin{abstract}
Despite very similar political, drug policy and HIV prevention backgrounds, HIV and HCV prevalence is considerably different in Hungary (low HIV and moderate HCV prevalence) and Lithuania (high HCV and moderate HIV prevalence). We compared the drug use profile of Hungarian $(n=215)$ and Lithuanian $(n=300)$ injecting drug users (IDUs). Overall, compared with IDUs in Hungary, IDUs in Lithuania often injected opiates purchased in liquid form ('shirka'), used and shared 2-piece syringes (vs. 1-piece syringes) disproportionately more often, were less likely to acquire their syringes from legal sources and had significantly more experience with injected and less experience with non-injected drugs. It may not be liquid drugs per se that contribute to a higher prevalence of HCV and/or HIV, but it is probably factors associated with the injecting of liquid drugs, such as the wide-spread use and sharing of potentially contaminated 2-piece syringes acquired often from non-legal sources, and syringe-me-
\end{abstract}

diated drug sharing with 2-piece syringes. Scaling up substitution therapy, especially heroin replacement, combined with reducing the supply of liquid drugs may decrease the prevalence of high-risk injecting behaviours related to the injecting of liquid drugs and drug injecting-related infections among IDUs in Lithuania. Copyright $\odot 2010$ S. Karger AG, Basel

\section{Introduction}

Hungary (with a population of 10 million) and Lithuania (with a population of 3 million) joined the European Union in 2004 after shaking off decades of Soviet rule in the early 1990s [1,2]. Despite these similarities, the prevalence of HIV and HCV is very different in these 2 countries. Historically, only a few cases of HIV were diagnosed among injecting drug users (IDUs) in these countries between 1992 and 1996 [3]. However, between 1997 and 2007, while the HIV incidence in Hungary stayed low (between 0 and 3 cases per year), it increased in Lithuania (between 23 and 379 cases per year) [3]. Studies in the past years among IDUs in Hungary detected no HIV preva-

\section{KARGER}

๑ 2010 S. Karger AG, Basel

Fax +41613061234 E-Mail karger@karger.ch www.karger.com www.karger.com/ear
V. Anna Gyarmathy

European Monitoring Centre for Drugs and Drug Addiction

Cais do Sodré, PT-1249-289 Lisbon (Portugal)

Tel. +351 21121 0200, Fax +351 213584441

E-Mail anna.gyarmathy@emcdda.europa.eu 
lence $[4,5]$, while the prevalence of HIV among IDUs in Lithuania is as high as $10 \%$ in certain populations [5]. Concerning HCV, between 1995 and 2007, at most 14 new IDU cases in 1 year were detected in Hungary, compared with as many as 55 in 1 year in Lithuania [6], and HCV prevalence among IDUs is about $40 \%$ in Hungary and as high as $90 \%$ in Lithuania [7].

While no historical data are available on trends of injecting in the 2 countries, currently, problem drug use is more prevalent in Hungary (about 35 per 10,000 population aged $15-65$ ) than in Lithuania (17 per 10,000 population aged 15-64) and IDU is less common in Hungary (about 6 per 10,000 population aged 15-64) than in Lithuania (about 13 per 10,000 population aged $15-64$ ) $[8,9]$. Data on trends of harm reduction reveal that HIV prevention programmes started around the same time in both countries. Syringe exchange programmes are legal (since 1994 in Hungary and since 1997 in Lithuania), and syringes can be purchased legally in pharmacies [10]. In addition, drug treatment is widely available in both Hungary (since 1995) and Lithuania (since 1996) [11]. Drug injecting patterns may be different in the 2 countries: while Hungarian IDUs inject drugs that are purchased almost exclusively in powder form and use predominantly 1-piece syringes, Lithuanian IDUs often inject drugs purchased in liquid form and often with 2-piece syringes (1-piece or low dead space syringes that have no removable needle and hold very little fluid when the plunger is fully depressed vs. 2-piece or high dead space syringes that have removable syringes and hold relatively large amounts of fluid when the plunger is fully depressed) [4, 12-14].

Understanding the differences in the characteristics of populations with a similar HIV prevention background but different infection prevalence patterns may help develop appropriate interventions to decrease the prevalence of drug-related infections among high-prevalence populations and keep the prevalence low in low-prevalence populations. The aim of this analysis was to compare the individual background among Hungarian and Lithuanian IDUs and patterns of population mixing susceptibility, drug use, syringe use and sharing, structural background markers, and attitude and knowledge, and further, to provide suggestions for interventions.

\section{Methods}

\section{Setting and Participants}

IDUs in both countries were recruited with traditional methods to reach hidden populations: in Budapest, Hungary, between October 2005 and December 2006 using street outreach, and in
Vilnius, Lithuania, between March 2008 and May 2009 from the needle exchange programme of the Lithuanian AIDS Centre. In addition, participants in both cities were asked to bring in other IDUs who may be eligible to participate in the study. In Hungary, $29 \%$ of participants were street recruited and $71 \%$ of participants were brought in by other participants, and in Lithuania, $6 \%$ of participants were recruited from the needle exchange programme and $94 \%$ were brought in by other participants. Those who selfreported injecting drugs in the past 30 days or were $\geq 18$ years old were eligible to participate. Data on recruitment success were not collected or were not possible for those who were invited to participate by participants already enrolled in the study, thus differences between participants and non-participants cannot be assessed. Self-report of injecting drugs was confirmed in both cities by inspecting injecting marks. Participants received a cash payment of HUF 2,000 (about EUR 8) in Budapest and food coupons worth LTL 20 (about EUR 8) in Vilnius for participation, and HUF 500 (about EUR 2) in Budapest and coupons worth LTL 10 (about EUR 4) in Vilnius for bringing in other eligible participants. After signing an informed consent, eligible participants were administered an about 2-hour-long structured face-to-face survey, after which they received counselling about drug-related infectious diseases and their prevention and provided blood samples to be tested for infectious diseases. In Hungary, the Abbott ELISA test confirmed by Western blot was used for HIV antibody screening, and the HCV EIA 3.0 procedure for encoded antigens (recombinant c100-3, HC-31 and HC-34) confirmed by recombinant immunoblot assay was used for $\mathrm{HCV}$ antibody screening. In Lithuania, the Abbott ELISA test Genscreen HIV1/2 (Biorad) confirmed by Western blot was used for HIV antibody screening, and the HCV EIA 3.0 (orthoclinical diagnostics) procedure for encoded antigens (recombinant c100-3, HC-31 and HC-34) confirmed by recombinant immunoblot assay was used for HCV antibody screening.

The wording of the questions that were used for this analysis was identical in both cities, except where specified. The questionnaires were originally in English, translated into Hungarian and Lithuanian, back translated, and altered, if necessary. The institutional review boards at the National Development and Research Institutes, Inc., in New York, N.Y., USA, and the Hungarian Academy of Sciences in Budapest, Hungary, approved all human subjects procedures for the study in Budapest. The institutional review boards at the Johns Hopkins Bloomberg School of Public Health, Baltimore, Md., USA, and the Lithuanian AIDS Centre approved all human subjects procedures for the study in Vilnius.

\section{Measures and Variables}

Individual background variables were age and gender (male vs. female). Population mixing susceptibility variables were ethnicity (Roma, and, in Lithuania only, Russian and Polish), the number of languages participants spoke (1, 2, 3, 4 or more), any travel outside the capital and abroad in the past 12 months. Drug use pattern characteristics were calculated based on the questions 'how old were you when you first tried (drug name)', 'have you ever injected (drug name)', 'how often did you use (drug name) in the past 30 days injected', 'how often did you use (drug name) in the past 30 days non-injected'. The questions were asked for altogether 24 drugs ['korong' (a mixture of hallucinogens) was included only in Hungary, and opiates purchased in liquid form ('shirka') and amphetamines purchased in liquid form were in- 
cluded only in Lithuania], and the open-ended 'other drug' $(<5 \%$ in each sample reported drugs other than those listed). Based on answers to these questions, we calculated the age at first use of legal drugs (alcohol or tobacco), age at first use of any illegal drugs, age at first drug injecting, the number of years as a nonIDU, the number of drugs ever tried and ever injected, and the number of drugs (any and daily) injected and used non-injected in the past 30 days. Participants were also asked about which drug they injected most often in the past 30 days. Injecting equipment use and sharing variables were: using any 2 -piece syringes (vs. using only 1-piece syringes), a composite variable assessing syringe sharing (reporting any receptive or distributive syringe sharing), and a composite variable assessing the sharing of injecting equipment other than syringes [any cookers or filters, or squirting drugs from one syringe into another syringe (syringe-mediated drug sharing)] in the past 30 days.

Structural background markers assessed ever and currently being in treatment. In addition, participants were asked what percent of syringes they obtained from the syringe exchange themselves or through somebody else (primary or secondary exchange) [15], from the pharmacy, or from their dealers. In Lithuania only, participants reported what drugs they most often injected with 1-piece and 2-piece syringes (where participants were able to select 1 of the above listed drugs). A combined HCV/HIV disclosure attitude variable was created based on agreement with both of the following statements: 'those who are HCV infected should tell their injecting partners' and 'those who are HIV infected should tell their injecting partners'. A composite HCV/ HIV knowledge score was calculated based on the number of correct answers to the 8 questions whether $\mathrm{HCV}$ and, respectively, HIV is transmitted sexually, with used syringes, with other used injecting equipment, and whether there is a vaccine. Sexual risk variables assessed, in the past 30 days, the number of sex partners, the number of sexual acts and whether condoms were used every time.

\section{Statistical Analysis}

$\chi^{2}$ analysis assessed differences in categorical variables, and the $t$ test assessed differences in continuous variables between participants in Hungary versus Lithuania. Variables with at least marginal $(p<0.20)$ association in the univariate analysis were chosen for logistic regression analysis. Multivariate logistic regression with forward selection was used to identify the set of variables that showed a significant $(p<0.05)$ association with recruitment location. A structured forward selection procedure was used, whereby groups of highly correlated variables were examined and variables that were selected within the groups were then combined into a group for the final variable selection. Maximum likelihood estimates with corresponding $\mathrm{p}$ values are reported. Data management and analysis were preformed in SAS version 9.2. Bar chars were created in Excel.

\section{Results}

Altogether, 215 participants were interviewed in Hungary and 300 in Lithuania. Of the 186 who were tested in Hungary, 37\% were HCV infected and nobody tested positive for HIV, and of the 297 who were tested in Lithuania, $88 \%$ tested positive for HCV and $10 \%$ for HIV - significant differences between the 2 study sites (table 1 ). Just under a quarter in both sites were females (non-significant difference), and Hungarian IDUs were significantly younger. About a third (30\%) of IDUs in Lithuania most often injected drugs purchased in liquid form, while none of the IDUs in Hungary mentioned liquid drugs in the 'other drug' category.

In the univariate analysis, with the exception of age at first use of illegal drugs and ever being in treatment, all the population mixing susceptibility characteristics, drug use patterns, injecting equipment use and sharing characteristics, structural background markers, as well as attitude and knowledge variables were significantly different (table 1,2). IDUs in Hungary used a higher number of non-injected drugs (fig. 1), while IDUs in Lithuania injected not only somewhat different, but also a higher number of drugs (fig. 2). While IDUs in Lithuania had a significantly higher number of sexual partners, there were no further significant differences in sexual risk characteristics.

Multivariate analysis (table 3) showed that IDUs in Lithuania were significantly more likely than IDUs in Hungary to engage in (either receptive or distributive) syringe sharing, use any 2-piece syringes, speak 3 or more languages, inject daily, know more about HIV and HCV, have injected a higher number of drugs both on a daily basis in the past 30 days and ever, and are older the first time of using any legal drugs (alcohol or tobacco). In addition, IDUs in Hungary were significantly more likely than IDUs in Lithuania to inject amphetamines, get all their syringes from legal sources (either the pharmacy or the needle exchange), and have used a higher number of non-injected drugs both on a daily basis in the past 30 days and ever.

We performed a post-hoc analysis of this sample and compared IDUs in Lithuania who ever in their lives injected opiates purchased in liquid form $(n=286)$ with those who never did $(n=14)$. Those IDUs who reported ever injecting liquid opiates had a significantly higher prevalence of both HCV (90 vs. $36 \%$ ) and HIV (10 vs. $0 \%$ ), and injecting liquid opiates showed a strong and significant association with $\mathrm{HCV}(\mathrm{OR}=18.0 ; 95 \% \mathrm{CI}=$ 5.5-59.2) even after controlling for years since first injecting in a preliminary bivariate logistic regression model. 
Table 1. Individual background, population mixing susceptibility, drug use patterns and syringe use and sharing among Lithuanian and Hungarian IDUs

\begin{tabular}{|c|c|c|c|}
\hline Characteristics & Hungary & Lithuania & $\mathrm{p}$ value \\
\hline Total & $215(100)$ & $300(100)$ & \\
\hline Tested positive for $\mathrm{HCV}^{1}$ & $69(37.1)$ & $260(87.5)$ & $<0.01$ \\
\hline Tested positive for HIV ${ }^{1}$ & $0(0)$ & $29(9.8)$ & $<0.01$ \\
\hline \multicolumn{4}{|l|}{ Individual background } \\
\hline \multicolumn{4}{|l|}{ Gender } \\
\hline Male & $166(77.2)$ & $229(76.3)$ & \\
\hline Female & $49(22.8)$ & $71(23.7)$ & 0.82 \\
\hline Age, years & $27.9 \pm 6.5$ & $29.8 \pm 7.6$ & $<0.01$ \\
\hline \multicolumn{4}{|l|}{ Population mixing susceptibility } \\
\hline \multicolumn{4}{|l|}{ Ethnicity ${ }^{2}$} \\
\hline Roma & $44(20.5)$ & $6(2.0)$ & $<0.01$ \\
\hline Russian & $\mathrm{N} / \mathrm{A}$ & $150(50.0)$ & \\
\hline Polish & $\mathrm{N} / \mathrm{A}$ & $50(16.7)$ & \\
\hline \multicolumn{4}{|l|}{ Number of languages participant speaks } \\
\hline Only one & $67(31.2)$ & $3(1.0)$ & \\
\hline Two & $90(41.9)$ & $89(29.7)$ & \\
\hline Three & $45(20.9)$ & $172(57.3)$ & \\
\hline Four or more & $13(6.0)$ & $36(12.0)$ & $<0.01$ \\
\hline Travelled outside the capital in the past 12 months & $138(64.2)$ & $137(45.7)$ & $<0.01$ \\
\hline Travelled outside the country in the past 12 months & $44(20.5)$ & $25(8.3)$ & $<0.01$ \\
\hline \multicolumn{4}{|l|}{ Drug use patterns } \\
\hline Age at first use of legal drugs (alcohol or tobacco), years & $12.4 \pm 3.0$ & $14.0 \pm 2.3$ & $<0.01$ \\
\hline Age at first use of any illegal drug, years & $15.0 \pm 5.3$ & $15.8 \pm 4.4$ & 0.09 \\
\hline Age at first drug injecting, years & $20.5 \pm 6.0$ & $19.2 \pm 4.4$ & $<0.01$ \\
\hline Years as non-injecting drug user & $5.5 \pm 5.3$ & $3.4 \pm 3.8$ & $<0.01$ \\
\hline Number of drugs ever tried & $12.1 \pm 4.4$ & $11.0 \pm 3.0$ & $<0.01$ \\
\hline Number of drugs ever injected & $4.4 \pm 2.9$ & $5.5 \pm 2.0$ & $<0.01$ \\
\hline Number of drugs injected in the past 30 days & $1.5 \pm 0.9$ & $2.9 \pm 1.2$ & $<0.01$ \\
\hline Number of drugs injected daily in the past 30 days & $0.4 \pm 0.5$ & $1.2 \pm 0.8$ & $<0.01$ \\
\hline Number of drugs non-injected in the past 30 days & $3.7 \pm 1.7$ & $2.9 \pm 2.0$ & $<0.01$ \\
\hline Number of drugs non-injected daily in the past 30 days & $1.6 \pm 0.9$ & $1.1 \pm 0.4$ & $<0.01$ \\
\hline Daily drug injecting & $91(42.3)$ & $273(91.0)$ & $<0.01$ \\
\hline \multicolumn{4}{|l|}{ Drug injected most often in past 30 days } \\
\hline Heroin & $147(68.4)$ & $198(66.0)$ & \\
\hline Amphetamine purchased in powder form & $61(28.4)$ & $12(4.0)$ & \\
\hline Drugs purchased in liquid form & $0(0.0)$ & $90(30.0)$ & \\
\hline Other drugs & $7(3.3)$ & $0(0)$ & $<0.01$ \\
\hline \multicolumn{4}{|l|}{ Injecting equipment use and sharing - past 30 days } \\
\hline \multicolumn{4}{|l|}{ Any use of 2-piece syringes } \\
\hline (vs. using only 1 -piece syringes) & $14(5.2)$ & $253(94.8)$ & $<0.01$ \\
\hline Any syringe/needle sharing (receptive or distributive) & $71(33.0)$ & $294(98.0)$ & $<0.01$ \\
\hline \multicolumn{4}{|l|}{ Any sharing of other injecting equipment } \\
\hline (cookers, filters, syringe-mediated drug sharing) & $133(61.9)$ & $285(95.0)$ & $<0.01$ \\
\hline
\end{tabular}

Figures in parentheses are percentages. N/A = Not assessed.

${ }^{1} 297$ participants were tested in Lithuania and 186 participants were tested in Hungary.

${ }^{2}$ More than 1 ethnic group could be checked. 
Table 2. Structural background markers, attitude and knowledge, and sexual risk characteristics of Lithuanian and Hungarian IDUs

\begin{tabular}{|c|c|c|c|}
\hline Characteristics & Hungary & Lithuania & $\mathrm{p}$ value \\
\hline Total & $215(100)$ & $300(100)$ & \\
\hline \multicolumn{4}{|l|}{ Structural background markers } \\
\hline Ever in treatment & $81(37.7)$ & $129(43.0)$ & 0.23 \\
\hline Currently in treatment & $45(20.9)$ & $16(5.3)$ & $<0.01$ \\
\hline All syringes used were sterile & $163(75.8)$ & $96(32.0)$ & $<0.01$ \\
\hline \multicolumn{4}{|l|}{ All syringes from the needle exchange } \\
\hline (primary or secondary exchange) & $88(40.9)$ & $42(14.0)$ & $<0.01$ \\
\hline All syringes from the pharmacy & $71(33.0)$ & $1(0.3)$ & $<0.01$ \\
\hline All syringes from either the needle exchange or the pharmacy & $194(90.2)$ & $114(38.0)$ & $<0.01$ \\
\hline Any syringes from the dealer & $2(0.9)$ & $108(36.0)$ & $<0.01$ \\
\hline \multicolumn{4}{|l|}{ Drugs most often injected with 1-piece syringe } \\
\hline (any 1 -piece syringe use, $n=169)$ & $\mathrm{N} / \mathrm{A}$ & & \\
\hline Heroin & & $151(89.4)$ & \\
\hline Drugs purchased in liquid form & & $3(1.8)$ & \\
\hline Amphetamine purchased in powder form & & $15(8.9)$ & \\
\hline \multicolumn{4}{|l|}{ Drugs most often injected with 2-piece syringe } \\
\hline (any 2-piece syringe use, $\mathrm{n}=253$ ) & $\mathrm{N} / \mathrm{A}$ & & \\
\hline Heroin & & $90(35.5)$ & \\
\hline Drugs purchased in liquid form & & $129(51.0)$ & \\
\hline Amphetamine purchased in powder form & & $30(11.9)$ & \\
\hline Other & & $4(1.6)$ & \\
\hline \multicolumn{4}{|l|}{ Attitude and knowledge } \\
\hline \multicolumn{4}{|l|}{ Agreement with both HIV and HCV infection } \\
\hline have to be disclosed to all injecting partners & $212(98.6)$ & $250(83.3)$ & $<0.01$ \\
\hline HIV and HCV knowledge score & $4.1(1.1)$ & $4.8(0.5)$ & $<0.01$ \\
\hline \multicolumn{4}{|l|}{ Sexual risk } \\
\hline \multicolumn{4}{|l|}{ Number of sexual partners in the past 30 days } \\
\hline None & $90(41.9)$ & $77(25.7)$ & \\
\hline One & $89(41.4)$ & $109(36.3)$ & \\
\hline Two or more & $36(16.7)$ & $114(38.0)$ & $<0.01$ \\
\hline Number of sexual acts in the past 30 days & $8.7 \pm 14.9$ & $7.5 \pm 12.7$ & 0.36 \\
\hline Always used condoms for sex & $23(10.7)$ & $21(7.0)$ & 0.14 \\
\hline
\end{tabular}

Figures in parentheses are percentages. N/A = Not assessed.

\section{Discussion}

This study compared individual backgrounds and patterns of population mixing susceptibility, drug use, syringe use and sharing, structural background markers, as well as attitude and knowledge among IDUs in Budapest, Hungary, and Vilnius, Lithuania, in order to gain insight into what may lie behind the differences in HIV and HCV prevalence in these populations. Overall, compared with IDUs in Hungary, IDUs in Lithuania often injected drugs purchased in liquid form, used and shared 2 -piece syringes disproportionately more often, were less likely to acquire their syringes from legal sources, and had more experience with injected and less experience with non-injected drugs.

Liquid drugs, the sharing of syringes and other injecting equipment, and syringe type go hand in hand, and together, may contribute to a risk environment that could explain the differences in HIV and HCV prevalence between Hungary and Lithuania. 'Shirka' (also known as hanka or kompot/kompót) is a home-made liquid opiate, which is cheaper than heroin, and is sold in large, preloaded syringes [16] mostly in Gypsy camps in Lithuania. Not only are the preloaded syringes potentially non-ster- 


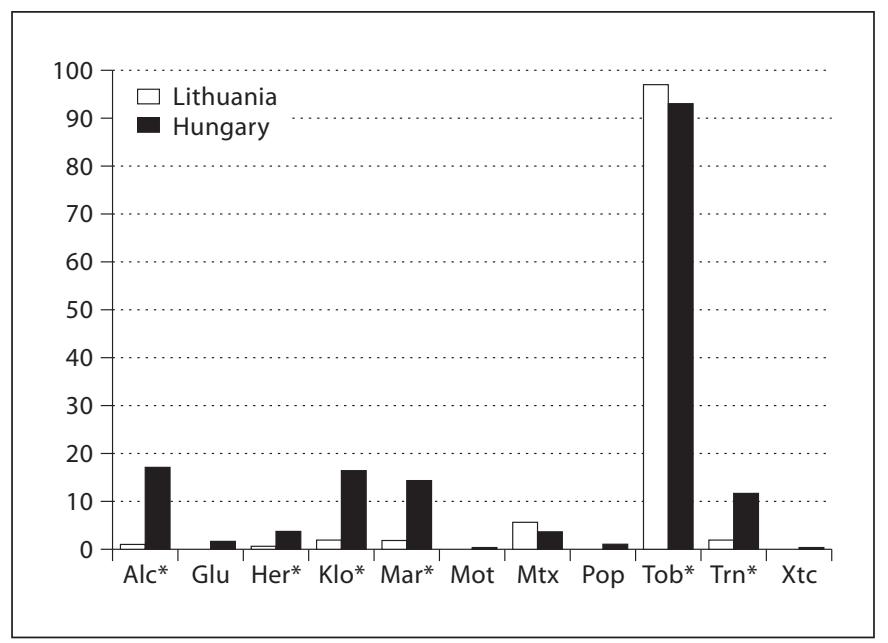

Fig. 1. Non-injected drugs used daily by Lithuanian and Hungarian IDUs. Alc = Alcohol; Glu = glue or inhalants; Her = heroin; Klo = klonopin or rivotril (i.e. clonazepam); Mar = marijuana; Mot $=$ methadone from sources other than treatment; Mtx = methadone from treatment; Pop = poppy tea; Tob = tobacco; Trn $=$ tranquilizers; Xtc $=$ ecstasy. ${ }^{*} \mathrm{p}<0.05$, statistically significant difference between proportions.

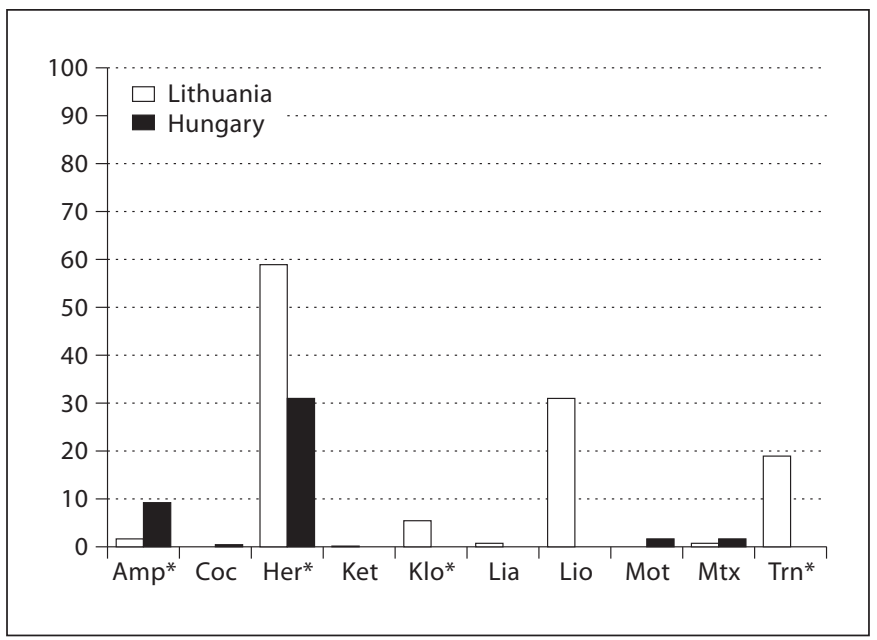

Fig. 2. Drugs injected daily by Lithuanian and Hungarian IDUs. Amp = Amphetamines (purchased in powder form); $\mathrm{Coc}=\mathrm{CO}-$ caine; Her = heroin; Ket = ketamine; Klo = klonopin or rivotril (i.e. clonazepam); Lia = amphetamines purchased in liquid form; Lio $=$ opiates purchased in liquid form; Mot = methadone from sources other than treatment; Mtx = methadone from treatment; $\operatorname{Tr} n=$ tranquilizers. ${ }^{*} \mathrm{p}<0.05$, statistically significant difference between proportions.

Table 3. Variables that were associated with recruitment location in multivariate logistic regression model

\begin{tabular}{lcc}
\hline & $\begin{array}{l}\text { Maximum likelihood } \\
\text { estimate }\end{array}$ & $\mathrm{p}$ value $\left(\chi^{2}\right)$ \\
\hline Any syringe/needle sharing (receptive or distributive) & 6.5693 & $<0.0001$ \\
Any use of 2-piece syringes (vs. using only 1-piece syringes) & 5.9863 & $<0.0001$ \\
Primary drug of injecting, amphetamine & -3.5097 & 0.0014 \\
All syringes from either the needle exchange or the pharmacy & -3.3663 & 0.0002 \\
Participant speaks 3 or more languages & 2.4135 & 0.0044 \\
Number of drugs non-injected daily in the past 30 days & -1.9324 & 0.0056 \\
Daily drug injecting & 1.8573 & 0.0279 \\
HIV and HCV knowledge score & 1.3817 & 0.0087 \\
Number of drugs injected daily in the past 30 days & 1.1464 & 0.0702 \\
Number of drugs ever tried & -0.7634 & 0.0003 \\
Number of drugs ever injected & 0.6166 & 0.0369 \\
Age at first use of any legal drug (alcohol or tobacco) & 0.3923 & 0.0112 \\
\hline
\end{tabular}

ile (maybe even contaminated with blood) [17], but they also prevent IDUs from using their own, sterile syringes from the pharmacy or the needle exchange. Furthermore, while cleaning syringes may considerably reduce the probability of infection [4], preloaded syringes may not be cleaned before sharing, because cleaning would flush out or dilute some or much of the drug in the syringe.
There is a link between liquid drugs and the sharing of syringes and other injecting equipment [12]: the content of the large, preloaded syringes is usually shared with other injectors, which requires either syringe sharing or the sharing of other injecting equipment (sharing of cookers or syringe-mediated drug sharing); the prevalence of both was high among IDUs in Lithuania. In ad- 
dition, our results show another link with liquid drugs, namely with syringe type: almost all drugs that were most often injected with 1-piece syringes in Lithuania were drugs sold in powder form, while the majority of drugs that were most often injected with 2-piece syringes were drugs sold in liquid form. (Participants explained that drugs purchased in liquid from have many floating particles that would clog the thin needles of 1-piece syringes, so 2-piece syringes, which have wider needles, are more suitable for injecting liquid drugs.) Two-piece syringes have more dead space between the plunger and the needle than 1-piece syringes and retain a larger amount of blood even after cleaning [18]. There is increasing evidence showing that the prevalence of both HIV and HCV infections is higher among IDUs who inject with 2-piece syringes compared with those who inject with 1-piece syringes only $[4,13,14]$.

However, based on prior research studies that defied the association between HIV and liquid drugs [19], it would be highly unfounded to suggest that liquid drugs by themselves are the reason for the higher prevalence of HCV and, especially, HIV in Lithuania. Abdala et al. [19] found that the potential for transmission from injection of liquid forms of heroin is dramatically reduced when IDUs inject with liquid heroin made from either poppies or opium gum (as opposed to heroin manufactured and sold as a solid product) because the cycles of heating, acidification and acetylation as well as some component of the poppies inactivate HIV. Thus, in the light of previous findings, our results suggest that it may not be liquid drugs per se that contribute to a higher prevalence of $\mathrm{HCV}$ and/or HIV. Instead, the role of liquid drugs may be to create a risk environment that promotes high-risk injecting practices, such as the wide-spread use and sharing of potentially contaminated 2-piece syringes acquired often from non-legal sources, syringe-mediated drug sharing and syringe-mediated drug sharing with 2-piece syringes - all of which were extremely high among the Lithuanian IDUs. Based on this and our post-hoc analysis, the role of drugs sold in liquid form should be further investigated in terms of their contribution to a risky injecting environment and high-risk injection practices. Such insight may provide an explanation to the paradox that while the process of liquid opiate production inactivates HIV, there are dramatically high levels of HIV among IDUs in, for example, the Ukraine who inject liquid opiates [20,21].

Drug injecting culture may also contribute to the differences in injecting and infections. IDUs in Hungary had less experience with injected and more experience with non-injected drugs. The reason for this may be that in Hungary, there is a centuries-old tradition of wine producing and moderate drinking [22] (as witnessed by the significantly lower age of IDUs in Hungary at first legal drug use, particularly of alcohol use, in this study). In Europe, southern countries with wine-producing traditions have less binge drinking and drunkenness than northern countries with no wine-producing traditions, probably because the idea of moderate consumption is integrated into everyday life [23]. The Hungarian wine drinking traditions may be reflected in Hungarian drug users' drug taking habits in a way that they prefer more 'moderate' drug taking [24]. However, this is only a hypothesis that cannot be confirmed in this study.

The finding that Lithuanian IDUs were more likely to speak 3 or more languages is certainly linked to the higher number of ethnic groups in Lithuania. While we did not assess fluency in these languages in the questionnaire, our interviewers in Hungary reported that most participants said they spoke only a little bit of, while our interviewers in Lithuania reported that most participants said they were fluent in the reported languages. Lack of language knowledge may prevent Hungarian IDUs from mixing with other IDUs visiting Hungary from higherprevalence countries, and thus, becoming infected, while language fluency, especially of Russian, in multi-ethnic Lithuania may contribute to more population mixing and opportunity for infection.

Limitations of this analysis include that comparing country differences is no evidence for causality. However, the goal of this analysis was not to imply causality but to provide new hypotheses and suggestions for further research. Another limitation is that while IDUs in Lithuania were initially recruited from the needle exchange programme, IDUs in Hungary were initially recruited from the street. However, most participants were recruited through other participants at both locations, which probably reduced the potential initial recruitment bias, and when we included frequency of syringe exchange attendance in the final multivariate model as a control variable, there was no change in the variable selection. Another limitation is that data collection in Vilnius started 2 years after data collection ended in Hungary. While the drug use population and habits may have changed during this time in Hungary, we believe this to be very unlikely since there was no change in the availability or quality of, or access to, prevention programmes targeting IDUs in Hungary, and the drug profile of these participants was very similar to those in our earlier studies [25], suggesting negligible changes in secular trends. A further limitation 
is that the injection of drugs purchased in liquid form was not assessed in Hungary. This drug category was not included because preliminary ethnographic findings showed that while some reported using liquid opioids in the past [26], these drugs were no longer available in Hungary. However, the questionnaire for this study included a question asking whether they used any drugs other than the ones mentioned and what these drugs were, and not only did nobody in Hungary mention 'kompót', but participants also commented on how exhaustive the drug list was. Another limitation is that the 2 populations were not random samples of the IDU populations in these 2 countries, which indicates that the representativeness of and generalization from these findings may be limited. A range of differences, both measured and unmeasured, may also contribute to the differences in HIV and HCV among the 2 IDU populations. While the differences in $\mathrm{HIV}$ and HCV prevalence may be a result of differences in the implementation of harm reduction interventions (a quantitative aspect of HIV/HCV infection risk), our findings provide suggestions for further exploring the role of liquid opiates and 2-piece syringes (a qualitative aspect of $\mathrm{HIV} / \mathrm{HCV}$ infection risk).

This study highlights that the availability of largescale HIV prevention programmes (such as legal access to sterile syringes and drug treatment) may not be enough to keep the prevalence of drug-related blood-borne infections low when the risk environment [16] is such that it considerably contributes to high-risk injecting. One such risk environment in Lithuania seems to be the widespread injecting of drugs sold in liquid form, leading to high-risk injecting, such as the wide-spread use and sharing of potentially contaminated 2-piece syringes acquired often from non-legal sources, syringe-mediated drug sharing and syringe-mediated drug sharing with 2-piece syringes. Although this hypothesis needs to be further tested, it suggests that a possible intervention to reduce HIV and HCV among IDUs in Lithuania would be to reduce the prevalence among them of injecting drugs sold in liquid form, especially liquid opiates. This could be accomplished by a combination of supply and demand reduction. Supply reduction would involve increasing police activities, to reduce the sale of drugs sold in liquid form. However, this alone may lead to the illegal sales of other drugs and a shift in the drug market [27] and may add to the pressure on Roma, Russian and Polish minorities. To counterbalance the unwanted effect of such supply reduction, there needs to be a parallel reduction in the demand for those new illegal drugs by increasing the availability of and access to legal drugs that meet the needs of active IDUs who are not ready or willing to stop injecting at that time [28]. Methadone maintenance treatment has been available in Lithuania since 1996 and in Hungary since 1995, high-dosage buprenorphine treatment in Lithuania since 2002, and buprenorphine/naloxone combination in Hungary since 2007 [11]. However, these treatment forms may not suit the needs of active drug injectors who do not wish to stop or reduce drug injecting. A treatment form that is more suitable for such a population is heroin-assisted treatment, which has been shown to significantly decrease the injecting of street drugs, engaging in syringe sharing, alcohol consumption and the prevalence of HCV and maybe HIV infections [29-37]. Heroin-assisted treatment is now the standard treatment in 6 European Union member states (Belgium since 2007, Denmark since 2008, Germany and Spain since 2003, The Netherlands since 1998, and the United Kingdom since the 1920s) [11], but not yet in either Hungary or Lithuania. Lithuanian authorities may want to consider adopting heroin-assisted treatment as a way to decrease the demand for and the prevalence of injecting opiates sold in liquid form, and thus, the use and sharing of (potentially contaminated) 2-piece syringes, and, on the longer run, decrease the prevalence of drug-related blood-borne infections among IDUs, including a further spread of HIV. In addition, increasing the availability of and access to psychosocial treatment, peer self-help organizations and brief interventions in general medical settings may be useful tools of demand reduction in Lithuania as well [38].

This study provides initial data on an important but challenging topic. Research over the previous 25 years has made it clear that simple rates of syringe sharing and unprotected intercourse do not adequately explain crossnational (and sometimes within-country) variations in HIV prevalence among IDUs. Accordingly, cross-national studies like this are essential to help identify and clarify factors beyond simple risk behaviours that may help understand differences in HIV prevalence.

\section{Acknowledgement}

We would like to thank all participants and the study staff in Budapest and Vilnius. The Hungary study was funded by the United States National Institute on Drug Abuse, grant No. 5R01DA014515-02S1, and the Lithuania study was funded by the United States National Institute on Drug Abuse, grant No. R01DA016555. 


\section{References}

1 Wikipedia. Hungary. 2009. http://en.wikipedia.org/wiki/Hungary (accessed November 20, 2009).

2 Wikipedia. Lithuania. 2009. http://en.wikipedia.org/wiki/Lithuania (accessed November 20, 2009).

3 European Monitoring Centre for Drugs and Drug Addiction: HIV infections newly diagnosed in injecting drug users, by year of report from 1992 to 2007, (a) cases per million population, (b) number of cases and (c) population sizes. Statistical Bulletin 2009. http:// www.emcdda.europa.eu/stats09/inftab104.

4 Gyarmathy VA, Neaigus A, Mitchell MM, et al: The association of syringe type and syringe cleaning with $\mathrm{HCV}$ infection among IDUs in Budapest, Hungary. Drug Alcohol Depend 2009;100:240-247.

5 European Monitoring Centre for Drugs and Drug Addiction: Prevalence of HIV infection among injecting drug users in the EU, 2007 or most recent year available - summary table by country. Statistical Bulletin 2009. http://www.emcdda.europa.eu/stats09/inftab1.

6 European Monitoring Centre for Drugs and Drug Addiction: Notified cases of hepatitis $\mathrm{C}$ infection among injecting drug users in the EU: (a) total number of cases where transmission route known, (b) number of IDU cases, and (c) percentage of IDUs amongst all cases with known risk factor. Statistical Bulletin 2009. http://www. emcdda.europa.eu/stats09/inftab105.

7 European Monitoring Centre for Drugs and Drug Addiction: Prevalence of hepatitis C infection among injecting drug users (\%), 1991 to 2007. Statistical Bulletin 2009. http:// www.emcdda.europa.eu/stats09/inftab111.

8 European Monitoring Centre for Drugs and Drug Addiction: Country overview: Hungary. 2009. http://www.emcdda.europa.eu/ publications/country-overviews/hu.

9 European Monitoring Centre for Drugs and Drug Addiction: Country overview: Lithuania. 2009. http://www.emcdda.europa.eu/ publications/country-overviews/lt.

10 European Monitoring Centre for Drugs and Drug Addiction: Year of introduction of needle and syringe programmes and types of programmes (NSP) available in 2007. Statistical Bulletin 2009. http://www.emcdda.europa.eu/stats09/hsrtab4.

11 European Monitoring Centre for Drugs and Drug Addiction: Year of introduction of methadone maintenance treatment (MMT), high-dosage buprenorphine treatment (HDBT), heroin-assisted treatment, slow-release morphine and suboxone. 2008. http:// www.emcdda.europa.eu/stats09/hsrtab1.
12 Hartnoll R, Gyarmathy VA, Zabransky T: Variations in problem drug use patterns and their implications for harm reduction; in Rhodes T (ed): Harm Reduction: Evidence, Impacts and Challenges - EMCDDA Scientific Monograph. Lisbon, European Monitoring Centre for Drugs and Drug Addiction, 2010.

13 Zule WA, Desmond DP, Neff JA: Syringe type and drug injector risk for HIV infection: a case study in Texas. Soc Sci Med 2002; 55:1103-1113.

14 Zule WA, Bobashev G: High dead-space syringes and the risk of HIV and HCV infection among injecting drug users. Drug Alcohol Depend 2009;100:204-213.

15 Snead J, Downing M, Lorvick J, et al: Secondary syringe exchange among injection drug users. J Urban Health 2003;80:330-348.

16 Rhodes T, Mikhailova L, Sarang A, et al: Situational factors influencing drug injecting, risk reduction and syringe exchange in Togliatti City, Russian Federation: a qualitative study of micro risk environment. Soc Sci Med 2003;57:39-54.

17 Bobkov AF, Selimova LM, Khanina TA, et al: Human immunodeficiency virus type 1 in illicit-drug solutions used intravenously retains infectivity. J Clin Microbiol 2005;43: 1937-1939.

18 Zule WA, Ticknor-Stellato KM, Desmond DP, et al: Evaluation of needle and syringe combinations. J Acquir Immune Defic Syndr Hum Retrovirol 1997;14:294-295.

19 Abdala N, Grund JP, Tolstov Y, et al: Can home-made injectable opiates contribute to the HIV epidemic among injection drug users in the countries of the former Soviet Union? Addiction 2006;101:731-737.

20 Booth RE, Kennedy J, Brewster T, et al: Drug injectors and dealers in Odessa, Ukraine. J Psychoactive Drugs 2003;35:419-426.

-21 Booth RE, Mikulich-Gilbertson SK, Brewster JT, et al: Predictors of self-reported HIV infection among drug injectors in Ukraine. J Acquir Immune Defic Syndr 2004;35:82-88.

22 Wikipedia. Hungarian wine. 2009. http:// en.wikipedia.org/wiki/Hungarian_wine (accessed November 20, 2009).

23 Kuntsche E, Rehm J, Gmel G: Characteristics of binge drinkers in Europe. Soc Sci Med 2004;59:113-127.

24 Neaigus A, Gyarmathy VA, Miller M, et al: Transitions to injecting drug use among noninjecting heroin users: social network influence and individual susceptibility. J Acquir Immune Defic Syndr 2006;41:493-503.

25 Rácz J, Gyarmathy VA, Neaigus A, et al: Injecting equipment sharing and perception of HIV and hepatitis risk among injecting drug users in Budapest. AIDS Care 2007;19:5966
26 Gyarmathy VA, Neaigus A, Ujhelyi E, et al: Strong HIV and hepatitis disclosure norms and frequent risk behaviors among Hungarian drug injectors. Drug Alcohol Depend 2006;82:S65-S69.

27 Topp L, Day C, Degenhardt L: Changes in patterns of drug injection concurrent with a sustained reduction in the availability of heroin in Australia. Drug Alcohol Depend 2003; 70:275-286.

28 Prochaska JO, Redding CA, Evers KE: The transtheoretical model and stages of change; in Glanz K, Lewis FM, Rimer BK (eds): Health Behavior and Health Education - Research and Practice. San Francisco, JosseyBass, 1997, pp 60-84.

-29 Haasen C, Verthein U, Degkwitz P, et al: Heroin-assisted treatment for opioid dependence: randomised controlled trial. Br J Psychiatry 2007; 191:55-62.

30 Steffen T, Christen S, Blattler R, et al: Infectious diseases and public health: risk-taking behavior during participation in the Swiss program for a medical prescription of narcotics (PROVE). Subst Use Misuse 2001;36: 71-89.

31 Steffen T, Blattler R, Gutzwiller F, et al: HIV and hepatitis virus infections among injecting drug users in a medically controlled heroin prescription programme. Eur J Public Health 2001;11:425-430.

32 Márványkövi F, Rácz J: Alacsony-küszöbủ, droghasználókat ellátó szolgáltatások jellemzői Magyarországon, 2004-ben. Addiktológia (Addictologia Hungarica) 2005;4: 431-459.

33 Gilbert M, Wong E, Spencer D, et al: Recommended use of point-of-care HIV tests. B C Med J 2007;49:177.

34 Verthein U, Bonorden-Kleij K, Degkwitz P, et al: Long-term effects of heroin-assisted treatment in Germany. Addiction 2008; 103 : 960-966; discussion 967-968.

35 Judd A, Rhodes T, Johnston LG, et al: Improving survey methods in sero-epidemiological studies of injecting drug users: a case example of two cross-sectional surveys in Serbia and Montenegro. BMC Infect Dis 2009;9:14

36 British Columbia Centre for Disease Control: Client counselling guidelines for use with point of care HIV test kits. 2007. http:// www.bccdc.ca/NR/rdonlyres/3CD32769CA46-4CB8-9B7C-75F24B7FD59B/0/STI GF_CLIENT_COUNSELLING_GUIDELINES_POC_ESTMay3007.pdf (accessed April 3, 2010).

37 Respess RA, Rayfield MA, Dondero TJ: Laboratory testing and rapid HIV assays: applications for HIV surveillance in hard-toreach populations. AIDS 2001;15(suppl 3): S49-S59.

38 Babor TF, Caulkins JP, Edwards G, et al: Drug Policy and the Public Good. Oxford, Oxford University Press, 2010. 